\title{
Wound Rotor Doubly Fed Induction Machine with Radial Rotary Transformer
}

\author{
Maurício Ruviaro, Fredemar Rüncos \\ WEG Equipamentos Elétricos S.A. - Energia, Jaraguá do Sul - SC, Brazil \\ mauricior@weg.net, fredemar@weg.net \\ Nelson Sadowski \\ Department of Electrical Engineering, Universidade Federal de Santa Catarina, Florianópolis - SC, Brazil \\ nelson@grucad.ufsc.br
}

\begin{abstract}
This paper shows a wound rotor doubly fed induction machine in which the typical brushes and slip-rings are substituted by rotary transformers.

The advantages of rotary transformer usage, the doubly fed induction machine operation and the dimensioning of a radial rotary transformer are the main aspects presented in this study.

The use of analytical equations is a very interesting resource for the development of industrial software for the calculation of this kind of device.

Comparison between simulated and measured results shows the good approximation of the steady-state model with the reality of this equipment.
\end{abstract}

Index Terms - Alternating current machines, brushless machines, prototypes, rotary transformer, transformer calculation.

\section{INTRODUCTION}

The doubly fed induction machine is a useful motor for industrial application and a largely adopted generator in wind energy farms. Its speed and torque can be controlled by rheostats or frequency converter connected to the rotor winding, what allows the reduction of converter power just to a fraction of induction machine mechanical power, saving installation costs [1] - [7].

In this context, the benefits of the use of doubly fed induction machines are undeniable; nevertheless, to take advantages of them it is mandatory to provide electrical connection between the rotor winding and the rheostat or the frequency converter [1] - [8].

The most common way to access the rotor winding is by brushes and slip-rings. However, the mechanical contact between moving slip-rings and static brushes wears these components and involves high rate of maintenance. Powder generated by brushes wearing can be also prejudicial for motor insulation. Additionally, any fault on electrical contact can generate sparks, limiting this machine installation only to non-explosive environments [1] - [3].

The development of brushless technologies is very interesting for reducing maintenance costs and expanding the use of doubly fed induction machines to explosive atmospheres [1] - [8].

Many studies consider the use of two induction machines connected in cascade for obtaining 
brushless devices [4] - [8]. This solution is effective from the point of view of eliminating brushes and slip-rings, but introduces the superposition of two different torque curve behaviors. The result is a device with anomalous torque vs. speed curve in which synchronous speed is determined by the combination of the number of poles of each machine [4], [5]. Only the join of the induction machine with a device incapable to offer any resistance torque avoids any change on the typical shape of torque vs. speed curve [1].

Since the seventies, there are several studies with the aim of substituting brushes and slip-rings by contactless energy transfer systems, like, e.g., rotary transformers [9] - [18]. Initially, these devices were developed concerning spacecrafts applications, where the lack of reliability and high rate of maintenance of brushes and slip-rings are totally undesirable [9]. In [11], Papastergiou and Macpherson propose the rotary transformer as an alternative solution for contactless transfer of energy across the revolving frame of airborne electronic-scanning radar. In [17], Legranger et al. propose the replacement of gliding contacts of a wound rotor synchronous machine by a radial rotary transformer operating like a contactless transmission power system. Despite of some particularities, the majority of studies for rotary transformer involve applications where the transformer is submitted to frequencies of hundreds of $\mathrm{Hz}[9]-[18]$.

In [1] - [3] Ruviaro et al. present the use of a radial three-phase rotary transformer electrically connected to an induction machine rotor circuit as can be seen at Figure 1.

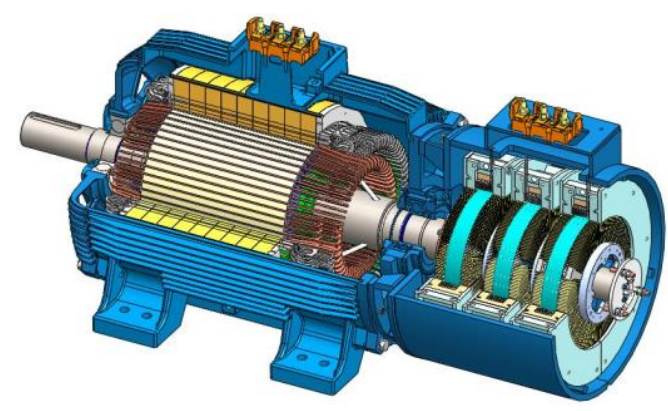

Figure 1 - Doubly fed three-phase induction machine with rotary transformer

The rotary transformer allows the access to rotor circuit without any mechanical contact. By using an appropriate drive, it is possible to control the induction machine operation as motor or generator at almost any speed, except at synchronous rotation.

The solution presented in [1] - [3] is very convenient for systems that must generate voltages with constant frequency through variable speed devices, like wind turbines [4] - [8].

\section{DOUBLy Fed INDUCTION MACHINE OPERATION}

The electrical connections for the use of converter in doubly fed induction machine operation are shown in Figure 2. This configuration allows controlling torque, speed, power factor and current of induction machine by a converter connected to the stator winding of the rotary transformer. Frequency 
converter controls the machine acting on amplitude, frequency and phase of the voltage applied in stator winding of rotary transformer [1] - [5].

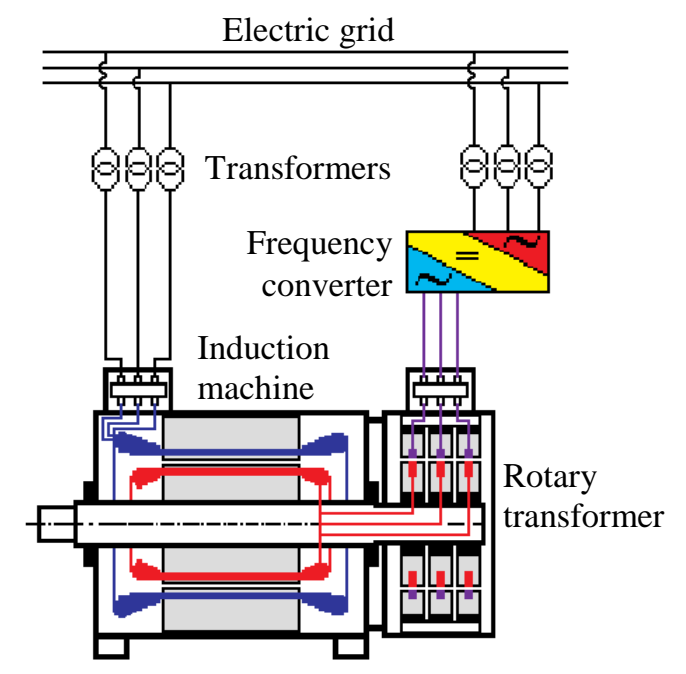

Figure 2 - Grid connection of the doubly fed three-phase induction machine with rotary transformer

When the stator winding of rotary transformer is connected to a resistive bank, it is possible to control only torque, speed and current [1] - [3].

Figure 3 presents the equivalent single-phase circuit that represents the connection between the induction machine and the rotary transformer.

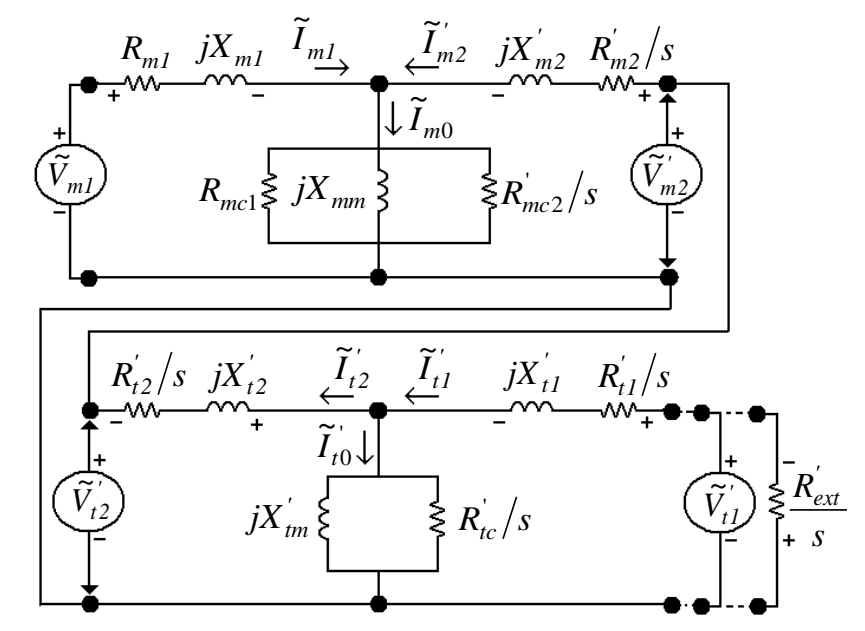

Figure 3 - Equivalent circuit of doubly fed induction machine with rotary transformer

where induction machine parameters mean:

$V_{m l}:$ stator winding single-phase voltage (in volts).

$V_{m 2}$ : rotor winding single-phase voltage (in volts).

$I_{m l}: \quad$ stator winding current (in amperes).

$I_{m 0}$ : exciting current (in amperes).

$I_{m 2}$ : rotor winding current (in amperes). 
$R_{m l}$ : stator winding resistance (in ohms).

$X_{m l}$ : stator winding leakage reactance (in ohms).

$R_{m c l}$ : stator iron resistance (in ohms).

$X_{m m}$ : magnetizing reactance (in ohms).

$R_{m c 2}$ : rotor iron resistance (in ohms).

$R_{m 2}$ : rotor winding resistance (in ohms).

$X_{m 2}$ : rotor winding leakage reactance (in ohms).

$s$ : $\quad$ slip.

and rotary transformer parameters mean:

$V_{t l}$ : stator winding single-phase voltage (in volts).

$V_{t 2}$ : rotor winding single-phase voltage (in volts).

$I_{t 1}: \quad$ stator winding current (in amperes).

$I_{t 0}$ : exciting current (in amperes).

$I_{t 2}: \quad$ rotor winding current (in amperes).

$R_{t l}$ : stator winding resistance (in ohms).

$X_{t l}$ : stator winding leakage reactance (in ohms).

$R_{t c}:$ iron resistance (in ohms).

$X_{t m}$ : magnetizing reactance (in ohms).

$R_{t 2}$ : rotor winding resistance (in ohms).

$X_{t 2}$ : rotor winding leakage reactance (in ohms).

$R_{e x t}: \quad$ external resistance (in ohms).

The equivalent circuit permits the steady-state analysis of the equipment operating as motor or generator. In the built prototype, all electrical connections were made in $\mathrm{Y}$, but the configuration of circuits with delta (D) connection is also possible.

\section{ROTARY TRANSFORMER DESIGN}

One of the most effective methods for rotary transformer designing is the use of analytical equations, what makes possible the obtaining of faster results.

\section{A. General constructive features}

The apparent power of three-phase rotary transformer $\left(S_{t}\right)$ is determined trough the induction machine rotor voltage $\left(V_{l m 2}\right.$ or $\left.V_{m 2}\right)$ and current $\left(I_{m 2}\right)$, as follow:

$$
S_{t}=\sqrt{3} \cdot V_{l m 2} \cdot I_{m 2}=3 \cdot V_{m 2} \cdot I_{m 2}
$$

where

$S_{t}$ : apparent power (in volt-amperes). 
$V_{l m 2}:$ rotor winding line voltage (in volts).

From these conditions, the general constructive features of rotary transformer can be determined, i.e., its core cross-section $\left(S_{t m}\right)$, the number of turns $\left(N_{t l}\right.$ and $\left.N_{t 2}\right)$ and the conductor cross-section $\left(S_{\text {condl } 1}\right.$ and $\left.S_{\text {cond } 2}\right)$.

Transformer core-cross section $S_{t m}$ (in square meters) can be calculated by:

$$
S_{t m}=K_{\text {core }} \cdot \sqrt{\frac{S_{t}}{3 \cdot f_{e n}}}
$$

where

$K_{\text {core }}$ : core usage factor.

$f_{e n}: \quad$ rated electric frequency (in hertz).

In this context, it is important to observe that $K_{\text {core }}$ represents a useful variable for optimization studies.

The number of rotor winding turns $\left(N_{t 2}\right)$ is calculated by:

$$
N_{t 2}=\frac{V_{m 2}}{4 \cdot 44 \cdot \sqrt{3} \cdot B_{\text {tmax }} \cdot S_{t m} \cdot f_{e n}}
$$

where

$B_{\text {tmáx }}$ : maximum magnetic flux density (in tesla).

The number of stator winding turns $\left(N_{t l}\right)$ is defined according the desired stator voltage $\left(V_{t l}\right)$ :

$$
N_{t 1}=\frac{N_{t 2} \cdot V_{t 1}}{V_{m 2}}
$$

The electrical connection between the induction machine and the rotary transformer establishes the same rotor current for both circuits:

$$
I_{t 2}=I_{m 2}
$$

In this way, rotary transformer stator current $\left(I_{t l}\right)$ is calculated by:

$$
I_{t 1}=\frac{N_{t 2} \cdot I_{t 2}}{N_{t 1}}
$$

Conductors' cross-sections ( $S_{\text {condl }}$ and $\left.S_{\text {cond } 2}\right)$ depend of the nominal current values $\left(I_{t l}\right.$ and $\left.I_{t 2}\right)$ and current density $\left(J_{\text {cond }}\right)$ :

$$
S_{\text {condl }}=\frac{I_{t 1}}{J_{\text {cond }}}
$$




$$
S_{\text {cond } 2}=\frac{I_{t 2}}{J_{\text {cond }}}
$$

where

$S_{\text {condl }}$ : stator conductor cross-section (in square meters).

$S_{\text {cond2 }}$ : rotor conductor cross-section (in square meters).

$J_{\text {cond }}$ : conductor current density (in amperes).

The total stator and rotor winding cross-sections $\left(S_{t c u l}\right.$ and $\left.S_{t c u 2}\right)$ are defined by:

$$
\begin{aligned}
& S_{t c u 1}=N_{t 1} \cdot S_{\text {cond } 1} \\
& S_{t c u 2}=N_{t 2} \cdot S_{\text {cond } 2}
\end{aligned}
$$

where

$S_{\text {tcul }}$ : stator winding cross-section (in square meters).

$S_{\text {tcu2 }}$ : rotor winding cross-section (in square meters).

Taking account the winding fill factor $\left(f_{\text {tfill }}\right)$, slots cross-sections $\left(S_{t s l o t l}\right.$ and $\left.S_{\text {tslot } 2}\right)$ are defined by:

$$
\begin{gathered}
S_{\text {tslot } 1}=\frac{S_{t c u 1}}{f_{t f i l l}} \\
S_{t s l o t 2}=\frac{S_{t c u 2}}{f_{\text {tfill }}}
\end{gathered}
$$

where

$S_{t s l o t l}$ : stator slot cross-section (in square meters).

$S_{t s l o t 2}$ : rotor slot cross-section (in square meters).

\section{B. General dimensions}

Determined the constructive features of the rotary transformer, it is possible to calculate the general dimensions indicated in Figures 4 and 5.

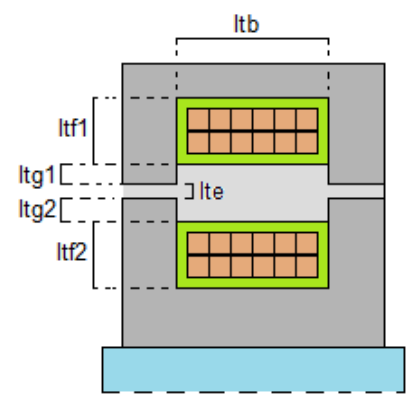

Figure 4 - Rotary transformer partial profile

Considering that $l_{t b}, l_{t e}, l_{t g l}$ and $l_{t g 2}$ are pre-defined values, $l_{t f 1}$ and $l_{t f 2}$ are defined by: 


$$
\begin{aligned}
& l_{t f 1}=\frac{S_{t s l o t 1}}{l_{t b}} \\
& l_{t f 2}=\frac{S_{t s l o t 2}}{l_{t b}}
\end{aligned}
$$

where

$l_{t f l}: \quad$ stator winding depth (in meters).

$l_{t f 2}$ : rotor winding depth (in meters).

$l_{t b}: \quad$ winding width (in meters).

$l_{t g l}: \quad$ stator gap length (in meters).

$l_{t g 2}: \quad$ rotor gap length (in meters).

$l_{t e}: \quad$ air-gap length (in meters).

The main rotary transformer diameters are presented in Figure 5.

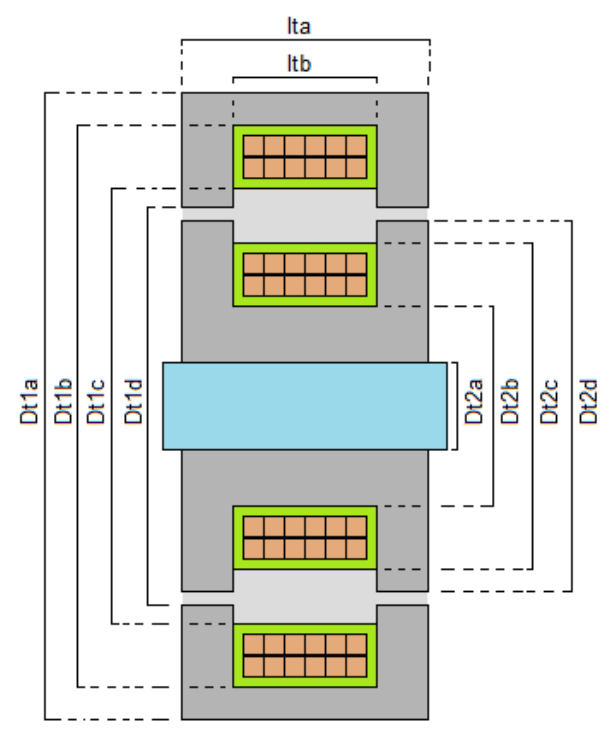

Figure 5 - Rotary transformer profile

Considering that transformer core is constituted by lamination placed longitudinal to the shaft, all diameters are calculated as following:

$$
\begin{gathered}
D_{t 2 b}=\frac{2 . S_{t m}}{\pi \cdot D_{t 2 a}}+D_{t 2 a} \\
D_{t 2 c}=D_{t 2 b}+2 \cdot l_{t f 2} \\
D_{t 2 d}=D_{t 2 c}+2 \cdot l_{t g 2} \\
D_{t 1 d}=D_{t 2 d}+2 \cdot l_{t e} \\
D_{t 1 c}=D_{t 1 d}+2 . l_{t g 1}
\end{gathered}
$$




$$
\begin{gathered}
D_{t 1 b}=D_{t 1 c}+2 \cdot l_{t f 1} \\
D_{t 1 a}=\frac{2 \cdot S_{t m}}{\pi \cdot D_{t 1 d}}+D_{t l b}
\end{gathered}
$$

where

$D_{\text {tla-d }}$ : stator diameters (in meters).

$D_{t 2 a-d}:$ rotor diameters (in meters).

The core width $l_{t a}$ (in meters) corresponds to:

$$
l_{t a}=\frac{2 \cdot S_{t m}}{\pi \cdot D_{t 2 a}}+l_{t b}
$$

Determined all transformer diameters, the winding average length $\left(l_{\text {tcul }}\right.$ and $\left.l_{\text {tcu2 } 2}\right)$ and air-gap $\left(l_{\text {tel2 }}\right)$ can also be calculated:

$$
\begin{aligned}
& l_{t c u 2}=\frac{\pi \cdot\left(D_{t 2 b}+D_{t 2 c}\right)}{2} \\
& l_{t e 12}=\frac{\pi \cdot\left(D_{t 1 d}+D_{t 2 d}\right)}{2} \\
& l_{t c u 1}=\frac{\pi \cdot\left(D_{t 1 b}+D_{t 1 c}\right)}{2}
\end{aligned}
$$

where

$l_{\text {tcul }}$ : stator winding average length (in meters).

$l_{\text {tcu2 }}$ : rotor winding average length (in meters).

$l_{\text {tel2 }}$ : air-gap average length (in meters).

The definition of average lengths is very important for the calculation of equivalent circuit parameters.

\section{Magnetic lengths}

The calculation of magnetic lengths is important for the determination of reluctance and magnetizing reactance.

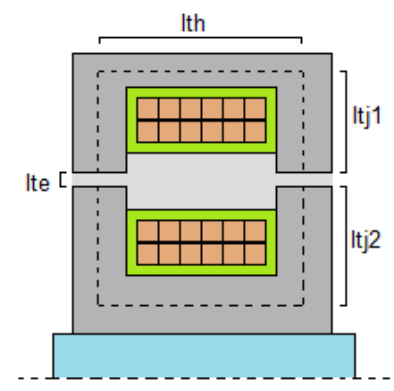

Figure 6 - Rotary transformer magnetic lengths 
Magnetic lengths observed in Figure 6 are defined by:

$$
\begin{gathered}
l_{t j 1}=\frac{1}{2} \cdot\left(\frac{D_{t 1 a}+D_{t l b}}{2}-D_{t 1 d}\right) \\
l_{t j 2}=\frac{1}{2} \cdot\left(D_{t 2 d}-\frac{D_{t 2 a}+D_{t 2 b}}{2}\right) \\
l_{t h}=\frac{l_{t a}+l_{t b}}{2}
\end{gathered}
$$

where

$l_{t j l}: \quad$ stator radial magnetic length (in meters).

$l_{t i 2}$ : rotor radial magnetic length (in meters).

$l_{t h}: \quad$ axial magnetic length (in meters).

\section{Equivalent circuit parameters}

Knowing transformer general dimensions and magnetic lengths, it is possible to calculate the equivalent circuit parameters. Resistances $R_{t 1}$ and $R_{t 2}$ correspond to:

$$
\begin{aligned}
& R_{t 1}=\frac{N_{t 1} \cdot l_{t c u 1} \cdot \rho}{S_{\text {cond } 1}} \\
& R_{t 2}=\frac{N_{t 2} \cdot l_{t c u 2} \cdot \rho}{S_{\text {cond } 2}}
\end{aligned}
$$

where

$\rho: \quad$ electric resistivity (in ohms. meter).

Leakage reactance $X_{t 1}$ and $X_{t 2}$ are calculated trough:

$$
\begin{aligned}
& X_{t 1}=2 \cdot \pi \cdot f_{e n} \cdot \mu_{0} \cdot \frac{N_{t 1}^{2} \cdot l_{t c u 1}}{l_{t b}} \cdot\left[\frac{l_{t f 1}}{3}+\left(l_{t g 1}+\frac{l_{t e}}{2}\right)\right] \\
& X_{t 2}=2 \cdot \pi \cdot f_{e n} \cdot \mu_{0} \cdot \frac{N_{t 2}^{2} \cdot l_{t c u 2}}{l_{t b}} \cdot\left[\frac{l_{t f 2}}{3}+\left(l_{t g 2}+\frac{l_{t e}}{2}\right)\right]
\end{aligned}
$$

where

$u_{0}$ : magnetic permeability of air (in henrys per meter).

The reluctance of magnetic circuit corresponds to:

$$
R_{t m}=\frac{1}{\mu_{0}} \cdot\left[\frac{2}{\mu_{r} \cdot S_{t m}} \cdot\left(l_{t h}+l_{t j 2}\right)+\frac{2}{\mu_{r} \cdot S_{t m l}} \cdot l_{t j 1}+\frac{2}{S_{t e}} \cdot l_{t e}\right]
$$


where

$S_{t m l}:$ stator leg core cross-section (in square meters).

$S_{t e}: \quad$ air-gap cross-section (in square meters).

Stator leg cross-section $\left(S_{t m l}\right)$ and air-gap cross-section $\left(S_{t e}\right)$ are determined by:

$$
\begin{aligned}
S_{t m l} & =D_{t l d} \cdot \pi \cdot \frac{\left(l_{t a}-l_{t b}\right)}{2} \\
S_{t e} & =l_{t e 12} \cdot \frac{\left(l_{t a}-l_{t b}\right)}{2}
\end{aligned}
$$

The magnetizing reactance $\left(X_{t m}\right)$ can be obtained through:

$$
X_{t m}=2 \cdot \pi \cdot f_{e n} \cdot \frac{N_{t 1}^{2}}{R_{t m}}
$$

To calculate the iron resistance, it is necessary to know the iron or core losses, which can be calculated by [3]:

$$
\begin{gathered}
w_{\text {core }}=\left[p_{f} \cdot\left(\frac{l_{\text {thic }} \cdot f_{\text {en }}}{25}\right)^{2}+p_{h} \cdot \frac{f_{\text {en }}}{50}\right] \cdot B_{\text {tmed }}^{2} \\
p_{\text {core }}=w_{\text {core }} \cdot m_{\text {core }}
\end{gathered}
$$

where

$w_{\text {core }}$ : iron losses (in watts per kilogram).

$p_{f}: \quad$ eddy current losses (in watts per kilogram).

$p_{h}: \quad$ hysteresis losses (in watts per kilogram).

$l_{\text {thic }}$ : lamination thickness (in meters).

$B_{\text {tmed }}:$ average magnetic flux density (in tesla).

$m_{\text {core }}$ : iron mass (in kilograms).

$p_{\text {core }}$ : iron losses (in watts).

The iron resistance $\left(R_{t c}\right)$ corresponds to:

$$
R_{t c}=\frac{V_{t 1}^{2}}{3 \cdot p_{\text {core }}}
$$

\section{MANUFACTURED PROTOTYPE}

According to the previous definitions, a rotary transformer was manufactured to be installed in a $90 \mathrm{~kW}$ prototype with the characteristics presented in Table I. 
TABLE I

Nominal DAta of THE PROTOTYPE

\begin{tabular}{lllllll}
\hline$V_{l m 1}$ & $I_{m 1}$ & $f_{e n}$ & poles & $P_{\text {shaft }}$ & $\mathrm{V}_{l m 2}$ & $I_{m 2}$ \\
\hline $690 \mathrm{~V}$ & $100 \mathrm{~A}$ & $60 \mathrm{~Hz}$ & 6 & $90 \mathrm{~kW}$ & $525 \mathrm{~V}$ & $110 \mathrm{~A}$ \\
\hline
\end{tabular}

where

$V_{l m l}:$ stator winding line voltage (in volts).

$P_{\text {shaft }}$ : mechanical power on shaft (in watts).

To achieve the requirements established by prototype data, dimensions of the rotary transformer are according to Table II.

TABLE II

ROTARY TRANSFORMER DIMENSIONS

\begin{tabular}{lllll}
\hline $\boldsymbol{D}_{t 1 a}$ & $\boldsymbol{D}_{t 1 b}$ & $\boldsymbol{D}_{t 1 d}$ & $\boldsymbol{l}_{\boldsymbol{t} \boldsymbol{a}}$ & $\boldsymbol{N}_{\boldsymbol{t} \boldsymbol{l}}$ \\
\hline $493 \mathrm{~mm}$ & $451 \mathrm{~mm}$ & $387 \mathrm{~mm}$ & $110 \mathrm{~mm}$ & 19 \\
\hline $\boldsymbol{D}_{t 2 a}$ & $\boldsymbol{D}_{t 2 b}$ & $\boldsymbol{D}_{t 2 d}$ & $\boldsymbol{l}_{\boldsymbol{t} \boldsymbol{b}}$ & $\boldsymbol{N}_{\boldsymbol{t} \boldsymbol{d}}$ \\
\hline $188 \mathrm{~mm}$ & $254 \mathrm{~mm}$ & $384 \mathrm{~mm}$ & $52 \mathrm{~mm}$ & 19 \\
\hline
\end{tabular}

Figure 7 presents the rotor and stator of the manufactured transformer.
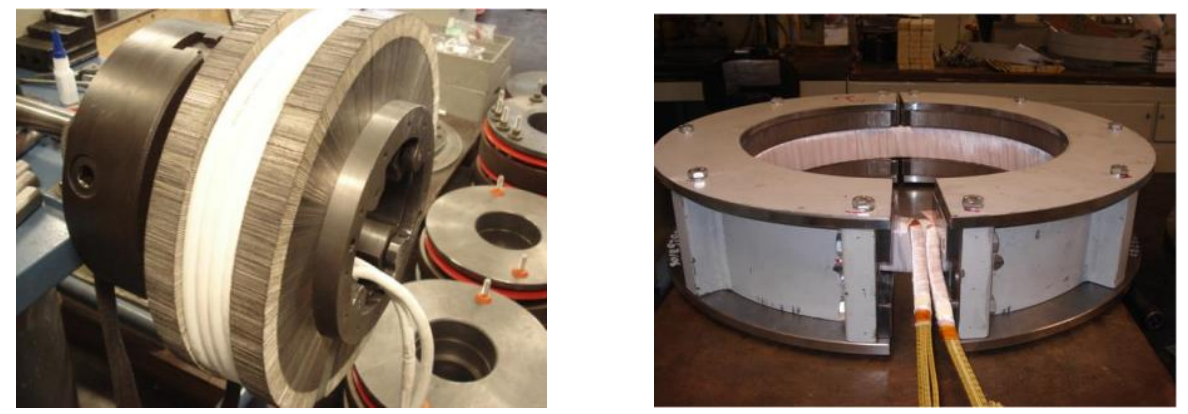

Figure 7 - Rotary transformer rotor and stator

The equivalent circuit parameters reflected to induction machine stator expressed in ohms are presented on table III.

TABLE III

Equivalent Circuit PARAMETERS IN OHMS $(\Omega)$ ) $40^{\circ} \mathrm{C}$

\begin{tabular}{lllllll}
\hline$R_{m 1}$ & $X_{m 1}$ & $R_{m 2}^{\prime}$ & $X_{m 2}^{\prime}$ & $R_{m c 1}$ & $X_{m m}$ & $R_{m c 2}^{\prime}$ \\
\hline 0.036 & 0.284 & 0.038 & 0.291 & 454.8 & 9.69 & 1136 \\
\hline$R_{t 1}^{\prime}$ & $X_{t 1}^{\prime}$ & $R_{t 2}^{\prime}$ & $X_{t 2}^{\prime}$ & $R_{t c}^{\prime}$ & $X_{t m}^{\prime}$ & - \\
\hline 0.019 & 0.131 & 0.017 & 0.139 & 124.0 & 3.24 & - \\
\hline
\end{tabular}

Applying the values presented at Table III on the equivalent circuit of Figure 3, it is possible to evaluate the steady-state performance of this prototype. 
Figure 8 exhibits the behavior of torque and current vs. speed curves for different values of external resistance.
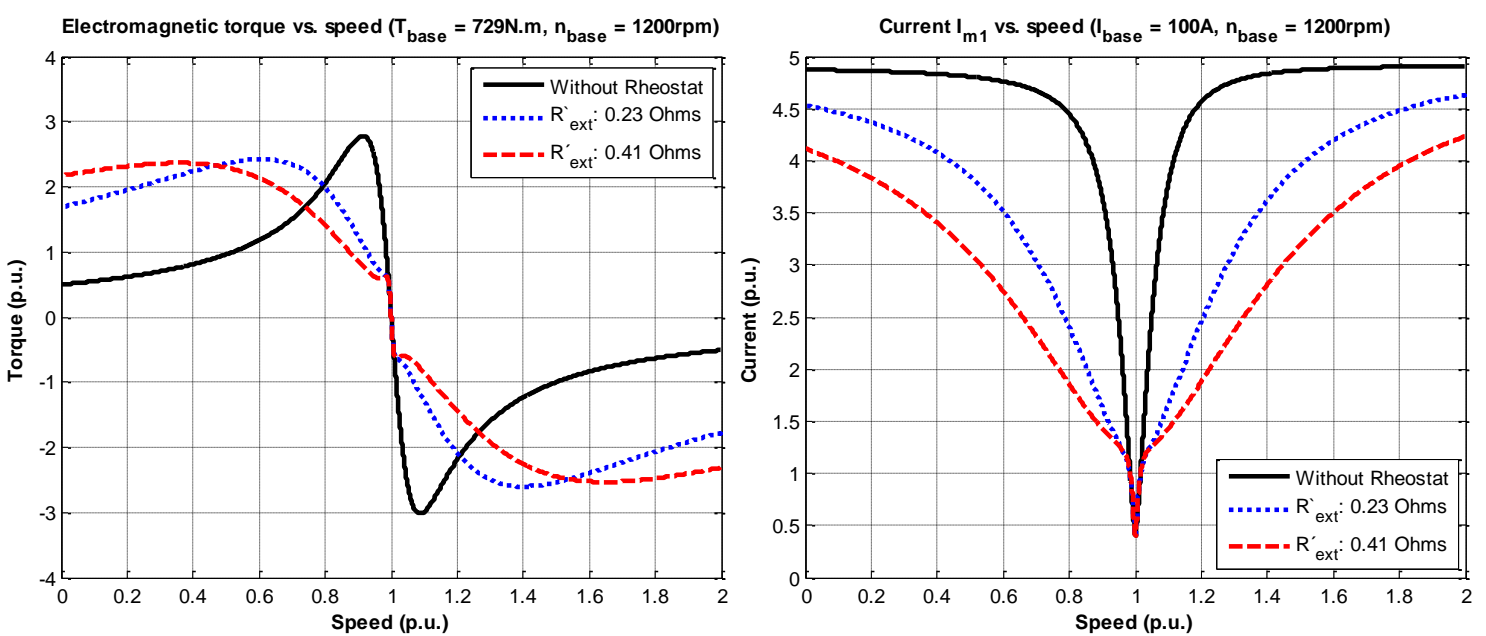

Figure 8 - Torque and current vs. speed curve for different external resistance values

As can be noted on Figure 8, the substitution of brushes and slip-rings by rotary transformers has the feature of keeping the typical response of the wound rotor induction machine when changed the external resistance value.

\section{LABORATORY MEASUREMENTS}

Fig. 9 presents laboratory scheme for load tests on the doubly fed induction machine.

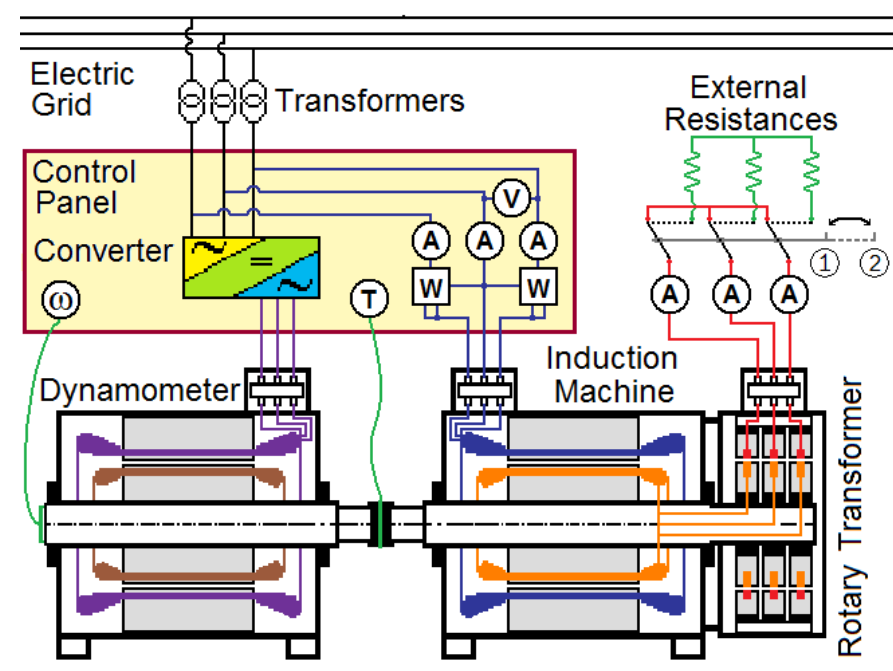

Fig. 8 - Laboratory scheme for load tests

In Fig. 9, it is possible to test doubly fed induction machine with transformer stator winding short-circuited or connected to resistances switching between position 1 and 2, respectively. The instrumentation has the following meanings:
A: amp meter
V: voltmeter
W: wattmeter
$\omega:$ encoder
T: torque transducer

Fig. 10 shows the comparison between measured and simulated torque and current vs. speed curve 
for short-circuited transformer stator winding.
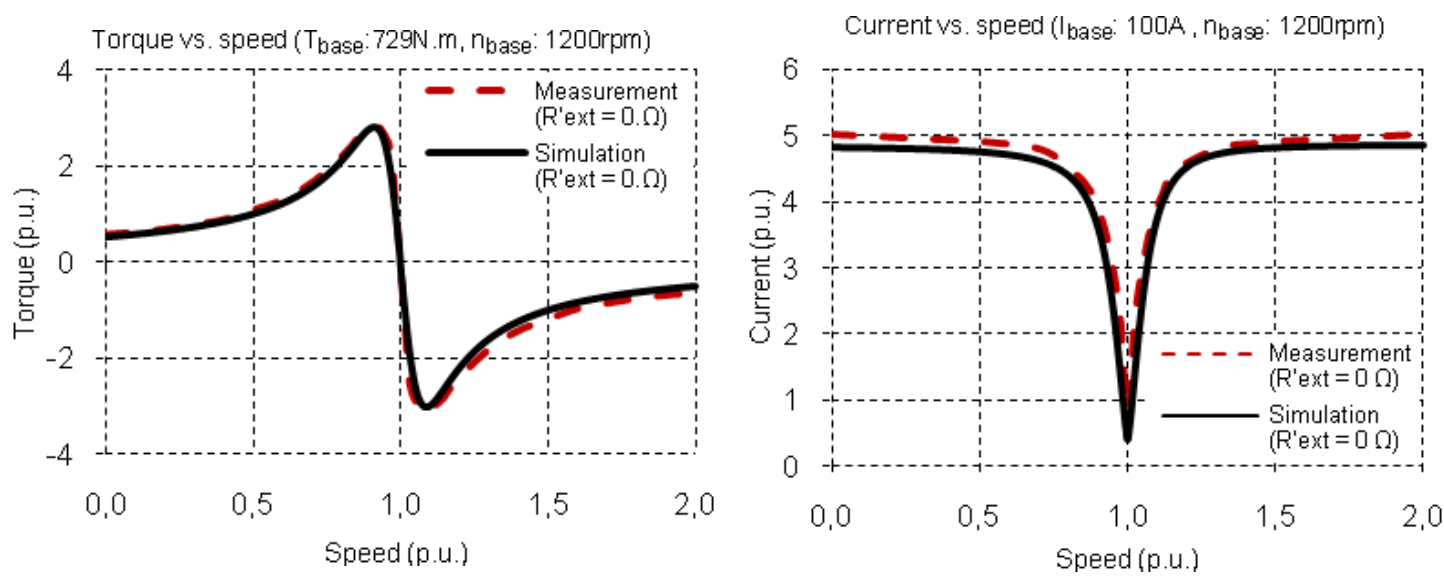

Fig. 10 - Torque and current vs. speed for transformer stator winding in short-circuit

Fig. 11 shows torque and current vs. speed curve considering the connection of an external resistance of $0.23 \Omega$.
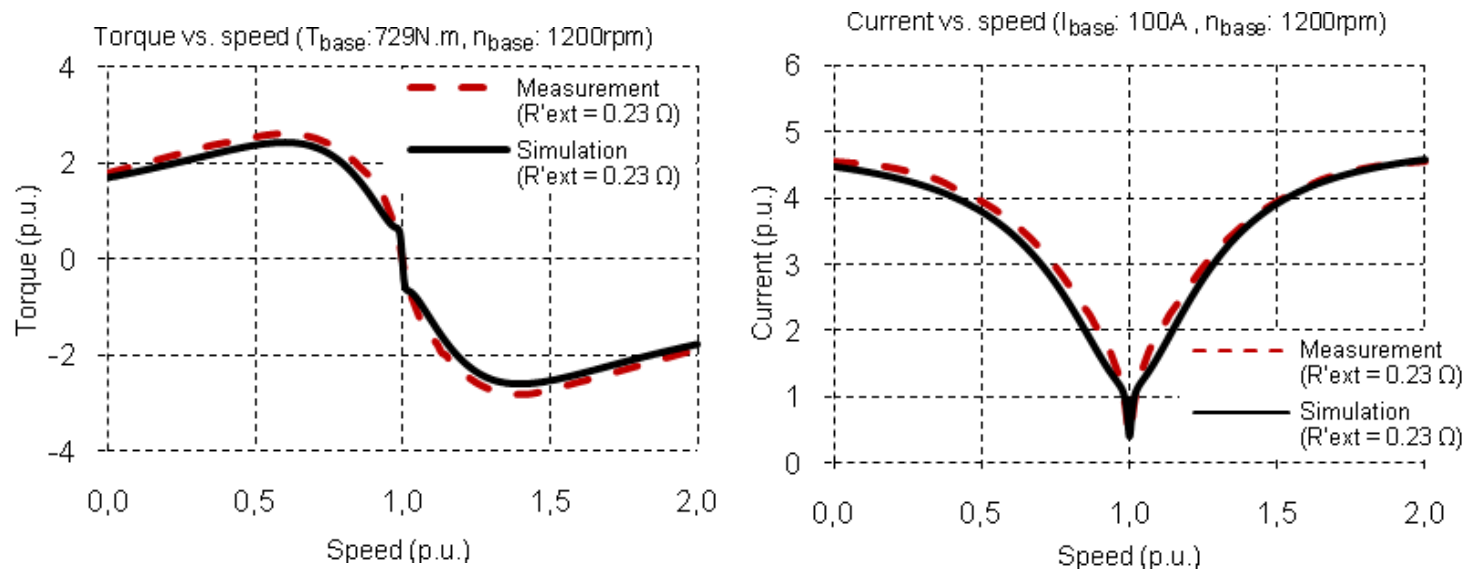

Fig. 11 - Torque and current vs. speed for transformer stator winding connected to external resistance of $0.23 \Omega$

Fig. 12 shows torque and current vs. speed curve when increasing external resistance to $0.41 \Omega$.
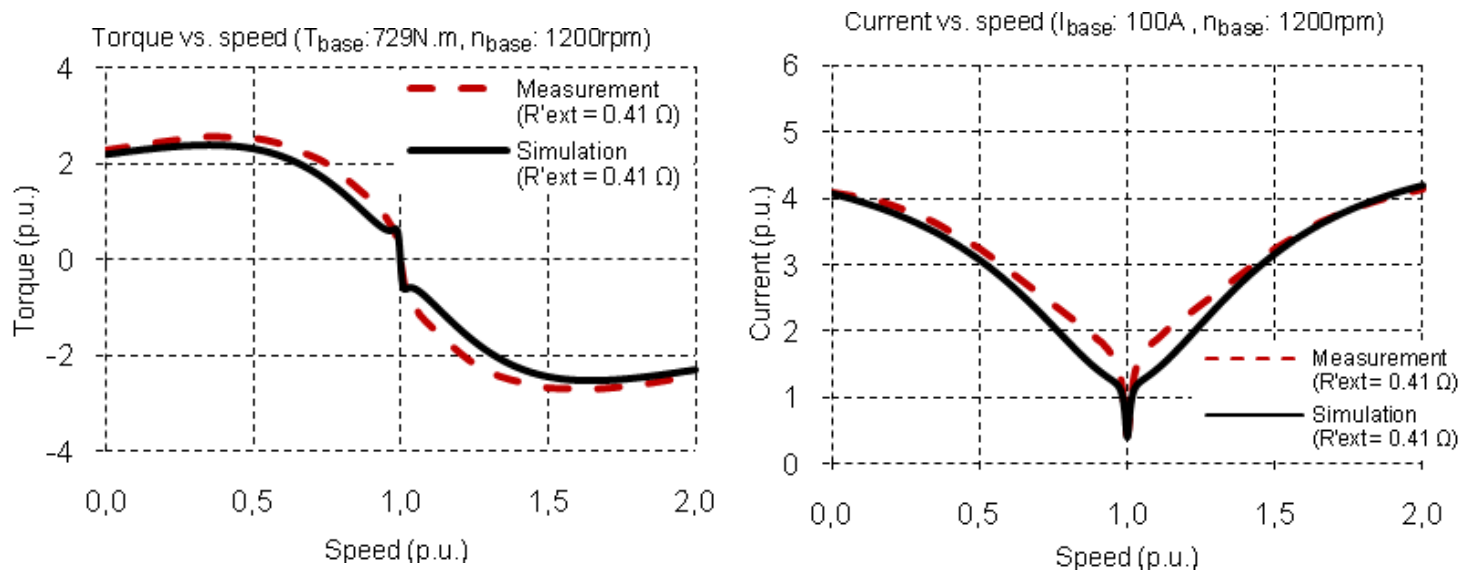

Fig. 12 - Electromagnetic torques for transformer stator winding connected to external resistance of $0.41 \Omega$ 
Figs. 10 - 12 show good agreement between measurement and simulation results, what confirms the assertively of the model. In Fig. 12, the difference between measured and simulated current curves is consequence of some saturation on rotary transformer due to external resistance increasing. This effect is originated by adoption of linear values for rotary transformer parameters on steady state model.

Tables VI and VII present measurement results for $25 \%$ to $125 \%$ load for motor and generator regime. In both cases, rotary transformer stator winding is short-circuited.

TABLE VI

INDUCTION MACHINE WITH ROTOR CONNECTED TO ROTARY TRANSFORMER (MOTOR OPERATION)

\begin{tabular}{llllll}
\hline \multicolumn{5}{c}{$\begin{array}{c}\text { Measurement results } \\
\text { Motor Operation }\end{array}$} \\
\hline Load & $\mathbf{2 5 \%}$ & $\mathbf{5 0 \%}$ & $\mathbf{7 5 \%}$ & $\mathbf{1 0 0 \%}$ & $\mathbf{1 2 5 \%}$ \\
\hline $\mathbf{V}_{\mathbf{l m} \mathbf{1}}(\mathbf{V})$ & 690 & 690 & 690 & $\mathbf{6 9 0}$ & 690 \\
$\mathbf{T}_{\text {shaft }}(\mathbf{N . m})$ & 182 & 364 & 546 & $\mathbf{7 2 8}$ & 910 \\
$\mathbf{P}_{\mathbf{m} 1}(\mathbf{k W})$ & 25.4 & 48.7 & 71.8 & $\mathbf{9 5 . 1}$ & 119 \\
$\mathbf{P}_{\text {shaft }}(\mathbf{k W})$ & 22.8 & 45.4 & 67.7 & $\mathbf{9 0 . 0}$ & 112 \\
$\mathbf{I}_{\mathbf{m} 1}(\mathbf{A})$ & 48.7 & 63.2 & 80.4 & $\mathbf{1 0 0}$ & 121 \\
$\mathbf{I}_{\mathbf{t 1}}(\mathbf{A})$ & 14.0 & 40.4 & 68.0 & $\mathbf{9 9 . 6}$ & 128 \\
Efficiency (\%) & 89.8 & 93.5 & 94.4 & $\mathbf{9 4 . 6}$ & 94.2 \\
Power factor $_{\text {Speed (rpm) }}$ & 0.44 & 0.64 & 0.75 & $\mathbf{0 . 8 0}$ & 0.82 \\
\hline
\end{tabular}

TABLE VII

INDUCTION MACHINE WITH ROTOR CONNECTED TO ROTARY TRANSFORMER (GENERATOR OPERATION)

\begin{tabular}{|c|c|c|c|c|c|}
\hline \multicolumn{6}{|c|}{$\begin{array}{l}\text { Measurement results } \\
\text { Generator Operation }\end{array}$} \\
\hline Load & $25 \%$ & $50 \%$ & $75 \%$ & $100 \%$ & $125 \%$ \\
\hline $\mathrm{V}_{\mathrm{Im} 1}(\mathrm{~V})$ & 690 & 690 & 690 & 690 & 690 \\
\hline $\mathbf{T}_{\text {shaft }}(\mathbf{N} . \mathbf{m})$ & 182 & 364 & 546 & 728 & 910 \\
\hline$P_{\mathrm{m} 1}(\mathrm{~kW})$ & 20.4 & 42.8 & 65.6 & 88.0 & 110 \\
\hline $\mathbf{P}_{\text {shaft }}(\mathbf{k W})$ & 23.0 & 46.1 & 69.4 & 92.8 & 116 \\
\hline $\mathbf{I}_{\mathrm{m} 1}(\mathrm{~A})$ & 46.1 & 60.0 & 77.2 & 96.2 & 116 \\
\hline $\mathbf{I}_{\mathbf{t} 1}(\mathrm{~A})$ & 13.0 & 37.4 & 64.6 & 94.9 & 121 \\
\hline Efficiency (\%) & 88.9 & 92.9 & 94.6 & 94.8 & 94.8 \\
\hline Power factor & 0.37 & 0.60 & 0.71 & 0.77 & 0.80 \\
\hline Speed (rpm) & 1205 & 1209 & 1214 & 1218 & 1223 \\
\hline
\end{tabular}


Power factor verified for this prototype is smaller than standard values for conventional 6 poles induction machines. Obviously, this reduction on power factor is explained by the inductive nature of rotary transformer $[1]$.

\section{CONCLUSION}

Rotary transformers are an interesting alternative to substitute brushes and slip-rings on wound rotor induction machines. Avoiding mechanical contact between rotating circuits, motors and generators maintenance can be drastically reduced.

The development of analytical equations for rotary transformer calculation is a good way for obtaining fast results, consisting in important resource for the development of industrial software for designing this device.

The realization of laboratory tests under the equipment shows concordance between steady-state simulation and measurement results.

\section{ACKNOWLEDGMENT}

Authors wish to thank WEG Equipamentos Elétricos S.A. for the prototype building and the use of its tests facilities.

\section{REFERENCES}

[1] M. Ruviaro, F. Rüncos, N. Sadowski, I. M. Borges, "Analysis and Tests Results of a Brushless Doubly Fed Induction Machine with Rotary Transformer", IEEE Transactions on Industrial Electronics, Early Access, 2011.

[2] M. Ruviaro, F. Rüncos, N. Sadowski, I. M. Borges, "Design and Analysis of a Brushless Doubly Fed Induction Machine with Rotary Transformer", in XIX International Conference on Electrical Machines (ICEM), Rome, Italy, 2010.

[3] M. Ruviaro, "Three-Phase Wound Rotor Asynchronous Machine Doubly Fed by Rotary Transformer" (in Portuguese), Master's dissertation, Universidade Federal de Santa Catarina, Brazil, 2011.

[4] F. Rüncos, "Double-Fed in Cascade Brushless Three-Phase Asynchronous Machine" (in Portuguese), Master's dissertation, Universidade Federal de Santa Catarina, Brazil, 2001.

[5] F. Rüncos, "Modeling, Project and Analysis of Brushless Double-Fed Three-Phase Asynchronous Machine" (in Portuguese), Doctoral thesis, Universidade Federal de Santa Catarina, Brazil, 2006.

[6] N. Patin, E. Monmasson, J.-P. Louis, "Modeling and Control of a Cascaded Doubly Fed Induction Generator Dedicated to Isolated Grid", IEEE Transactions on Industrial Electronics, vol. 56, no. 10, pp. 4207-4219, Oct 2009.

[7] S. Williamson, A. C. Ferreira, A. K. Wallace, "Generalised Theory of the Doubly-Fed Machine. Part 1: Analysis", IEE Proceedings Electrical Power Application, vol. 144, n. 2, pp. 111-122, Mar 1997.

[8] S. Williamson, A. C. Ferreira, "Generalised Theory of the Doubly-Fed Machine. Part 2: Model Verification and Performance", IEE Proceedings Electrical Power Application, vol. 144, n. 2, pp. 123-129, Mar 1997.

[9] S. H. Marx, R. W. Rounds, "A Kilowatt Rotary Power Transformer", IEEE Transactions on Aerospace and Electronic Systems, vol. AES-7, issue 6, pp. 1157-1163, Nov. 1971.

[10] J. Legranger, G. Friedrich, S. Vivier, J. C. Mipo, "Comparison of Two Optimal Rotary Transformer Designs for Highly Constrained Applications", in Proc IEEE Electric Machines \& Drives Conference (IEMDC), pp. 1546-1515, 2007.

[11] K.D. Papastergiou, D.E. Macpherson, "An Airborne Radar Power Supply With Contactless Transfer of Energy-Part I: Rotating Transformer", IEEE Transactions on Industrial Electronics, vol. 54, no. 5, pp. 2874-2884, Oct 2007.

[12] K.D. Papastergiou, D.E. Macpherson, "An Airborne Radar Power Supply With Contactless Transfer of Energy-Part II: Converter Design", IEEE Transactions on Industrial Electronics, vol. 54, no. 5, pp. 2885-2893, Oct 2007.

[13] K.D. Papastergiou, D.E. Macpherson, "Contact-less Transfer of Energy by means of a rotating transformer", in Proc. IEEE International Symposium on Industrial Electronics, pp. 1735-1740, 2005.

[14] K.D. Papastergiou, D.E. Macpherson, "Air-gap effects in inductive energy transfer", IEEE Power Electronics Specialists Conference, pp. 4092-4097, 2008.

[15] T.A. K. Stuart, H. R.J. Shamseddin, "Rotary Transformer Design with Fixed Magnetizing and/or Leakage Inductances", IEEE Transactions on Aerospace and Electronic Systems, AES-22, pp. 565, Sep 1986.

[16] J.P.C. Smeets, L. Encica, E.A. Lomonova, "Comparison of winding topologies in a pot core rotating transformer", presented at $12^{\text {th }}$ International Conference on Optimization of Electrical and Electronic Equipment (OPTIM), Brasov, Romania, 2010. 
[17] J. Legranger, G. Friedrich, S. Vivier, J. C. Mipo, "Design of a Brushless Rotor Supply for a Wound Rotor Synchronous Machine for Integrated Starter Generator", in Proc IEEE Vehicle Power and Propulsion Conference, pp. 236-241, 2007.

[18] C. Wm. T. McLyman, "Transformer and Inductor Design Handbook”, $3^{\text {rd }}$ ed., Chapter 19, Ed. New York: Marcel Dekker Inc., 2004. 